\title{
Quantitative assessment of human health risk posed by polycyclic aromatic hydrocarbons in urban road dust
}

\author{
Yukun Ma ${ }^{\mathrm{a}, \mathrm{b}}$, An Liu ${ }^{\mathrm{b}, \mathrm{c}, *}$, Prasanna Egodawatta ${ }^{\mathrm{b}}$, James McGree ${ }^{\mathrm{b}}$, Ashantha Goonetilleke ${ }^{\mathrm{b}}$ \\ a State Key Laboratory of Urban and Regional Ecology, Research Center for Eco-Environmental Sciences, Chinese Academy of Sciences, 18 Shuangqing Road, Beijing 100085, China \\ b Science and Engineering Faculty, Queensland University of Technology (QUT), GPO Box 2434, Brisbane 4001, Queensland, Australia \\ c College of Chemistry and Environmental Engineering, Shenzhen University, 518060 Shenzhen, China
}

\section{H I G H L I G H T S}

- Quantitative PAHs risk assessment approach in urban road dust was developed.

- This assessment approach was based on land use and traffic characteristics.

- Hotspots can be identified by using the approach to minimise the risk.

\section{A R T I C L E I N F O}

\section{Article history:}

Received 15 July 2016

Received in revised form 17 September 2016

Accepted 17 September 2016

Available online 23 September 2016

Editor: Adrian Covaci

\section{Keywords:}

Incremental lifetime cancer risk

Polycyclic aromatic hydrocarbons

Risk assessment

Urban road dust

Hydrocarbon pollution
G R A P H I C A L A B S T R A C T

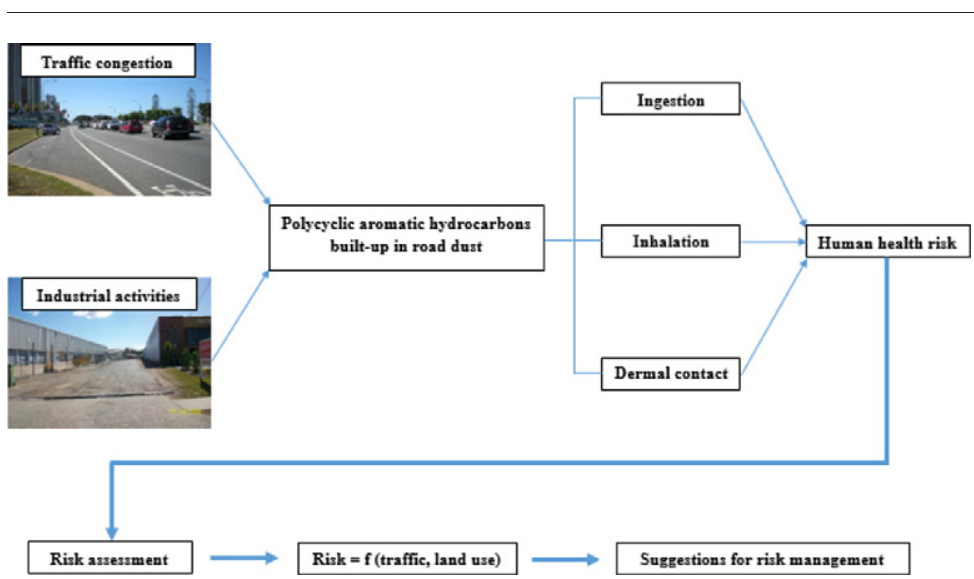

\begin{abstract}
A B S T R A C T
Among the numerous pollutants present in urban road dust, polycyclic aromatic hydrocarbons (PAHs) are among the most toxic chemical pollutants and can pose cancer risk to humans. The primary aim of the study was to develop a quantitative model to assess the cancer risk from PAHs in urban road dust based on traffic and land use factors and thereby to characterise the risk posed by PAHs in fine $(<150 \mu \mathrm{m})$ and coarse $(>150 \mu \mathrm{m})$ particles. The risk posed by PAHs was quantified as incremental lifetime cancer risk (ILCR), which was modelled as a function of traffic volume and percentages of different urban land uses. The study outcomes highlighted the fact that cancer risk from PAHs in urban road dust is primarily influenced by PAHs associated with fine solids. Heavy PAHs with 5 to 6 benzene rings, especially dibenzo[ $[a, h]$ anthracene $(\mathrm{D}[a] \mathrm{A})$ and benzo[a]pyrene $(\mathrm{B}[a] \mathrm{P})$ in the mixture contribute most to the risk. The quantitative model developed based on traffic and land use factors will contribute to informed decision making in relation to the management of risk posed by PAHs in urban road dust.
\end{abstract}

(c) 2016 Elsevier B.V. All rights reserved.
*. Corresponding author at: College of Chemistry and Environmental Engineering Shenzhen University, 518060 Shenzhen, China.

E-mail address: liuan@szu.edu.cn (A. Liu).

\section{Introduction}

Urban road dust contains large amounts of chemical pollutants such as heavy metals and organic compounds (Amato et al., 2009). Among 
these pollutants, polycyclic aromatic hydrocarbons (PAHs) are a large group of organic compounds which are mainly present in association with solids due to their hydrophobic properties (Dong and Lee, 2009). There are 16 PAHs identified by US EPA (1984) as priority pollutants due to their toxicity, potential to human exposure and prevalence in the urban environment. PAHs are carcinogenic to skin, lungs and bladder (Mahler et al., 2012), and the relationship between human cancer and PAHs has been well documented (Chen and Liao, 2006). There is potential for people to have direct contact with the pollutants in road dust whilst engaged in construction and recreational activities (Holmes et al., 1999), as well as being exposed to fugitive dust due to re-suspension (US EPA, 2002). For example, vehicle turbulence can entrain solids in the air, where people can ingest PAHs by respiration, particularly fine particles and also result in dermal contact. Consequently, PAHs in urban road dust can result in potential human health risks.

In order to assess the cancer risk, it is important to develop an understanding of the sources of PAHs in urban road dust. According to past studies, vehicular traffic and other anthropogenic activities such as industrial manufacturing related to urbanisation are two prominent sources of PAHs in urban areas (Brown and Peake, 2006; Gunawardena et al., 2014). For instance, vehicle exhaust emissions as a result of incomplete fuel combustion is a key source of PAHs (Rocher et al., 2004). In addition, various anthropogenic activities such as vehicle maintenance and industrial processes can also generate numerous PAHs (Fang et al., 2004). Due to the influential role of traffic and urban land use related activities in the generation of PAHs, the PAH load built-up on urban impervious surfaces such as in road dust varies with various traffic characteristics and land use characteristics (Shi et al., 2013; Gunawardena et al., 2014). As the risk is dependent on the build-up load of PAHs, the risk posed by PAHs in urban road dust can be related to traffic and land use characteristics inherent to an area.

A number of past research studies have quantitatively analysed the human health risk posed by PAHs in urban road dust (Dong and Lee, 2009; Wang et al., 2011). However, these studies are quite limited in their investigation of the role of various influential factors. For example, Wang et al. (2011) qualitatively compared the risk to people posed by PAHs in road dust collected from different residential, commercial, industrial and park areas. However, as the role of influential factors was not investigated and predictive models were not developed, assessments of this nature tends to be location specific (Yu et al., 2014; Peng et al., 2016). This is attributed to the fact that some influential factors such as land use are not easy to be quantified. Additionally, it is critical to select an appropriate technique to quantitatively relate the risk to the influential factors. Consequently, the in-depth investigation of the quantitative relationship between the risk and traffic and land use characteristics has received limited attention. The resulting knowledge gap constrains the practical estimation of the risk from PAHs associated with road dust in urban areas.

Accordingly, the primary aim of the study was to develop a quantitative model to assess the cancer risk from PAHs in urban road dust based on traffic and land use factors. It is important to note that although PAHs can be generated from various other sources such as long term atmospheric transportation of PAHs associated with black carbon (Tsai et al., 2001), the scope of this research study was focused on the influence of traffic and land use in the creation of potential health risk from the generation of PAHs. This is because traffic and land use activities are among the most common anthropogenic activities in the urban environment which generate PAHs. The qualitative influence of traffic and land use characteristics on the pollutant build-up in urban road dust has been supported by previous research (Gunawardena et al., 2014). As PAHs are commonly associated with fine particles $(<150 \mu \mathrm{m})$ which are easily re-suspended due to wind and vehicle related turbulence, thereby compounding the risk to people (Dong and Lee, 2009; Gunawardena et al., 2013), a further aim was to characterise the risk posed by PAHs in fine $(<150 \mu \mathrm{m})$ and coarse $(>150 \mu \mathrm{m})$ particles, individually. The model developed, as it is quantitatively based on traffic and land use factors, will contribute to informed decision making in relation to the management of risk posed by PAHs in urban road dust.

\section{Methods and materials}

\subsection{Study sites}

Four urbanised suburbs in Gold Coast, Queensland, Australia, representing different land use types were selected as study areas. These included Surfers Paradise (commercial), Benowa (mixed commercial and residential), Nerang (industrial) and Clearview Estate (residential). As the research study only considered road dust in the urban environment, industrial, commercial and residential land use types were analysed due to their significant contribution to the PAHs load in road dust (Gunawardena et al., 2012). This is also supported by the fact that residential, commercial and industrial areas are the typical land use types in the urban environment. Four road sites with different daily traffic volumes (DTV) [average vehicles/day] were selected from each suburb. The traffic volume data and land use characteristics of each study site are provided in Fig. 1. The traffic data for each study site was obtained from Gold Coast City Council. The percentage of commercial, industrial and residential land use area (C, I and R) [\%] encompassing a $1 \mathrm{~km}$ radius from the study site were considered as influential parameters in relation to pollutant composition in road dust. This was based on the outcomes of the study undertaken by Zhu et al. (2002) that 95\% of traffic generated fine particles are transported within $1 \mathrm{~km}$ from the source of origin. Different land use areas were demarcated using Google Earth (Google, 2015) maps and then C, I and R [\%] were calculated using ArcMap 10.1 software (ESRI, 2016).

\subsection{Study approach}

\subsubsection{Build-up samples collection}

The dust samples were collected from road surfaces at the study sites using a dry and wet vacuuming procedure (with efficiency of over 95\%) which has been adopted in previous research studies (Gunawardana et al., 2014). The sampling plot at each study site was a $1 \mathrm{~m}$ wide strip which covered the area from the kerb to the road centre line. This was to account for the possible variability in dust build-up across the road surface. It has been noted that a relatively higher pollutant load is built-up near the kerb (Novotny et al., 1985). Sample collection was conducted twice at the same study site to take into account the variation in PAH build-up on the road surface. Accordingly, a total of 32 samples were collected. Samples were collected after seven to nine antecedent dry days as the solids build-up load on a road surface is relatively stable after this period of time (Egodawatta et al., 2009). The dry and wet vacuuming procedure described in Gunawardana et al. (2014) was used for collecting both, dissolved and particulate form. The collected samples were preserved in deionised water in glass bottles under $4{ }^{\circ} \mathrm{C}$ until analysis.

\subsubsection{Laboratory testing}

Build-up samples were separated into two particle size fractions, $<150 \mu \mathrm{m}$ and $>150 \mu \mathrm{m}$, by wet sieving, and both fractions were tested for PAHs and total solids. As PAHs are highly hydrophobic, they are liable to associate with particulates in the aqueous environment rather than being soluble in water (Wu et al., 2013). Therefore, the influence of desorption of PAHs during wet sieving and sample storage was not considered. The separation of $<150 \mu \mathrm{m}$ and $>150 \mu \mathrm{m}$ was due to the differences in the build-up process of these two particle size fractions as identified by Wijesiri et al. (2016). As the samples were in dissolved and particulate form, the aqueous and particulate PAHs were separated by vacuum filtration and extracted separately. Aqueous PAHs were extracted by liquid-liquid extraction according to US EPA method 610 (US EPA, 1984). Particulate PAHs were extracted by accelerated solvent extraction (ASE) which met the requirements of US EPA method 3545 

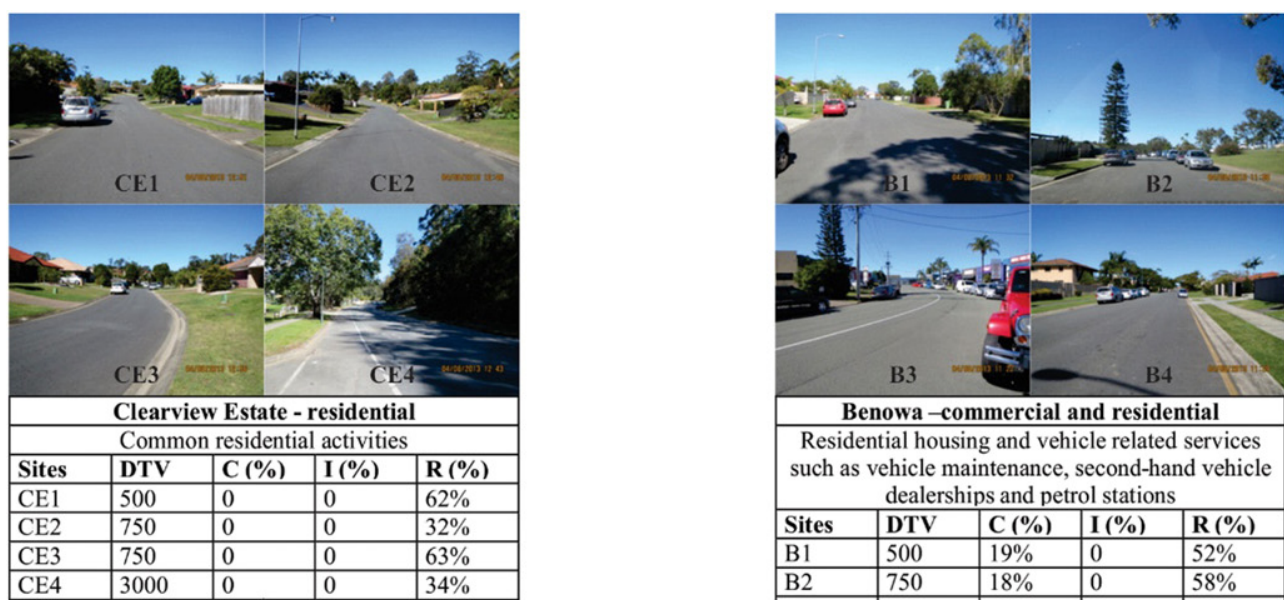

Benowa -commercial and residential

Residential housing and vehicle related services such as vehicle maintenance, second-hand vehicle dealerships and petrol stations

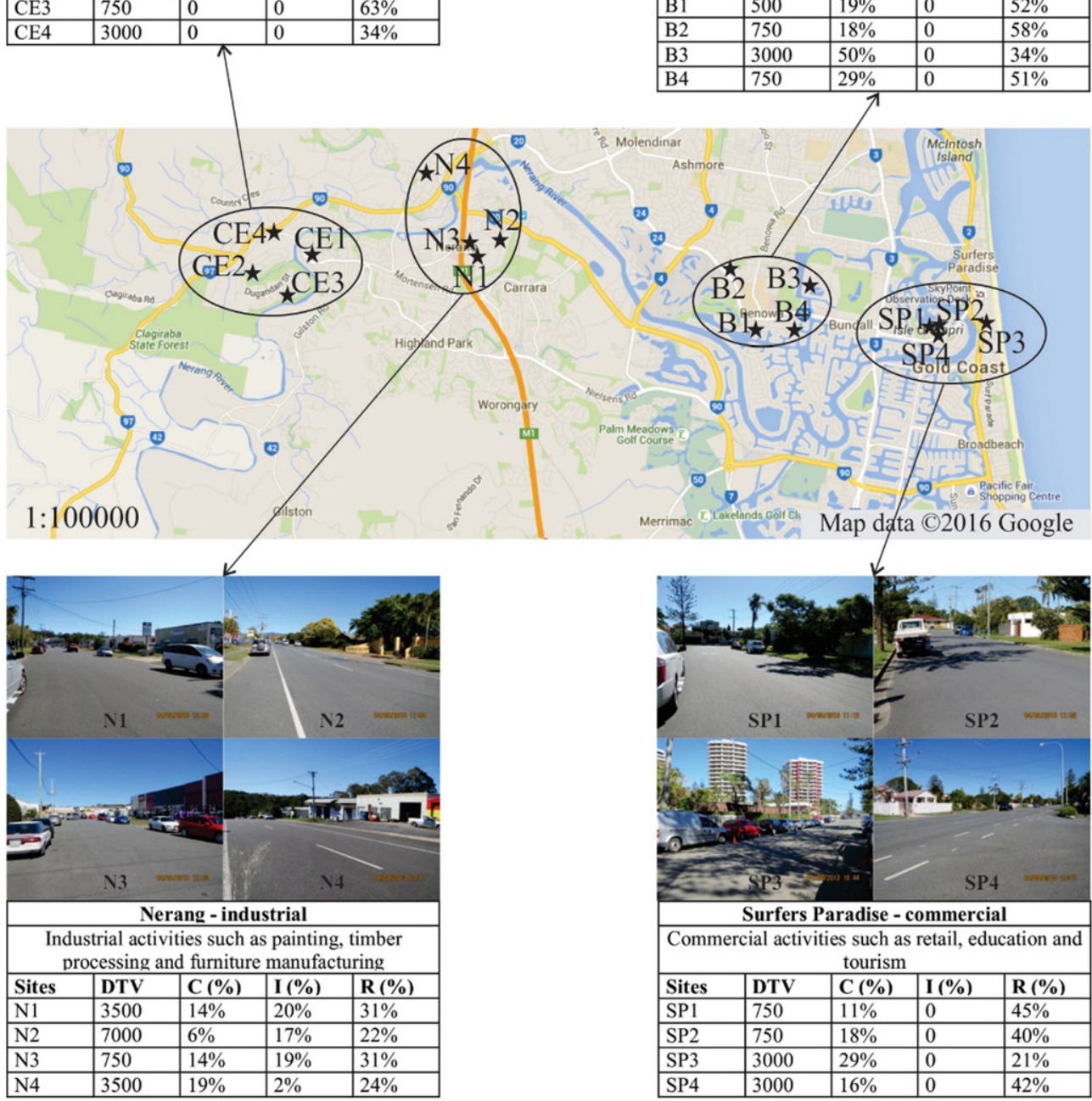

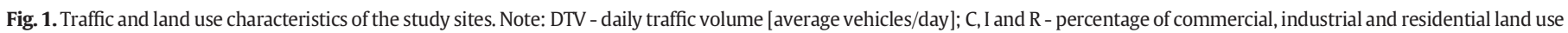
area [\%].

(US EPA, 1996). The concentration of both aqueous and particulate PAHs in the extract was analysed using a Shimadzu Gas Chromatograph Mass Spectrometer (GC-MS) TQ8030. Calibration standard used for GCMS method development was QTM PAH Mix standard purchased from Sigma Aldrich and it contained 15 PAH compounds including naphthalene (NAP), acenaphthylene (ACY), acenaphthene (ACE), fluorene (FLU), phenanthrene (PHE), anthracene (ANT), fluoranthene (FLA), pyrene (PYR), benz $[a]$ anthracene $(\mathrm{B}[a] \mathrm{A})$, chrysene (CHR), benzo[b]fluoranthene $(\mathrm{B}[b] \mathrm{F})$, benzo $[a]$ pyrene $(\mathrm{B}[a] \mathrm{P})$, indeno $(1,2,3-$ cd)pyrene (IND), dibenzo[a,h]anthracene (D[a]A), and benzo[ghi]perylene $(\mathrm{B}[g] \mathrm{P})$. It is noteworthy that benzo[ $k]$ fluoranthene $(\mathrm{B}[k] \mathrm{F})$ which is also included in the 16 US EPA PAHs is not contained in the QTM PAH Mix standard. Accordingly, 15 PAHs were tested in the laboratory analysis. Table 1 shows the statistics of PAH loads for $<150 \mu \mathrm{m}$ and $>150 \mu \mathrm{m}$ particle sizes. The PAH loads in Table 1 are the total concentration of both aqueous and particulate PAHs. It is evident that PAH loads were higher in $<150 \mu \mathrm{m}$ than in $>150 \mu \mathrm{m}$ particles and this is independent of PAHs species. Detailed data on the PAH loads at each road site in the two sampling episodes are summarised in Table S1 and S2 in the Supplementary Information.

As part of quality control and quality assurance, surrogate standard (Anthracene- $\mathrm{d}_{10}$ purchased from Sigma Aldrich) and internal standard (EPA 8270 Semivolatile Internal Standards Mix consisting of Acenaphthene- $\mathrm{d}_{10}$, Chrysene- $\mathrm{d}_{12}$, 1,4-Dichlorobenzene- $\mathrm{d}_{4}$, Naphthalene- 
Table 1

$\mathrm{PAH}$ loads in road dusts $[\mathrm{mg} / \mathrm{kg}]$.

\begin{tabular}{|c|c|c|c|c|c|c|c|c|c|c|c|c|c|c|c|c|}
\hline PAH loads & & NAP & ACY & ACE & FLU & PHE & ANT & FLA & PYR & $\mathrm{B}[a] \mathrm{A}$ & CHR & $\mathrm{B}[b] \mathrm{F}$ & $\mathrm{B}[a] \mathrm{P}$ & IND & $\mathrm{D}[a] \mathrm{A}$ & $\mathrm{B}[g] \mathrm{P}$ \\
\hline \multirow[t]{4}{*}{$<150 \mu \mathrm{m}$} & Max. & 0.172 & 0.063 & 0.030 & 0.060 & 0.603 & 0.072 & 0.666 & 1.370 & 0.114 & 0.424 & 0.220 & 0.596 & 0.317 & 0.155 & 1.340 \\
\hline & Min. & 0.025 & 0.003 & 0.001 & 0.000 & 0.031 & 0.007 & 0.006 & 0.059 & 0.007 & 0.030 & 0.020 & 0.017 & 0.000 & 0.009 & 0.000 \\
\hline & Mean & 0.078 & 0.025 & 0.006 & 0.024 & 0.230 & 0.031 & 0.166 & 0.444 & 0.049 & 0.153 & 0.101 & 0.137 & 0.111 & 0.056 & 0.412 \\
\hline & $\mathrm{SD}^{\mathrm{a}}$ & 0.043 & 0.018 & 0.007 & 0.019 & 0.147 & 0.019 & 0.181 & 0.341 & 0.035 & 0.115 & 0.067 & 0.141 & 0.091 & 0.046 & 0.384 \\
\hline \multirow[t]{4}{*}{$>150 \mu \mathrm{m}$} & Max. & 0.213 & 0.038 & 0.009 & 0.026 & 0.241 & 0.036 & 0.288 & 0.422 & 0.087 & 0.162 & 0.158 & 0.133 & 0.220 & 0.092 & 0.717 \\
\hline & Min. & 0.001 & 0.001 & 0.000 & 0.000 & 0.005 & 0.001 & 0.002 & 0.013 & 0.002 & 0.008 & 0.001 & 0.000 & 0.005 & 0.000 & 0.000 \\
\hline & Mean & 0.045 & 0.009 & 0.003 & 0.010 & 0.091 & 0.013 & 0.055 & 0.169 & 0.022 & 0.057 & 0.039 & 0.039 & 0.044 & 0.020 & 0.171 \\
\hline & SD & 0.051 & 0.009 & 0.003 & 0.008 & 0.062 & 0.011 & 0.071 & 0.107 & 0.026 & 0.048 & 0.043 & 0.039 & 0.064 & 0.024 & 0.188 \\
\hline
\end{tabular}

a Standard deviation.

$d_{8}$, Perylene- $d_{12}$, Phenanthrene- $d_{10}$ purchased from Sigma Aldrich) were used during the extraction and testing procedure, and field blanks and method blanks which were included also underwent the same procedures as the samples. The recovery of PAHs was checked by spiking the laboratory blank with a known amount of calibration standards. The recovery of aqueous PAHs and particulate PAHs was always within 80\%-96\% and $75 \%-105 \%$, respectively, which was considered acceptable in the analysis. Total solids in water samples was tested according to the US EPA method 2540B (APHA, 2004).

\section{Model development}

The risk assessment model was developed according to the procedure illustrated in Fig. 2. The build-up load of each PAH in the road dust was initially quantified as a mathematical function of traffic and

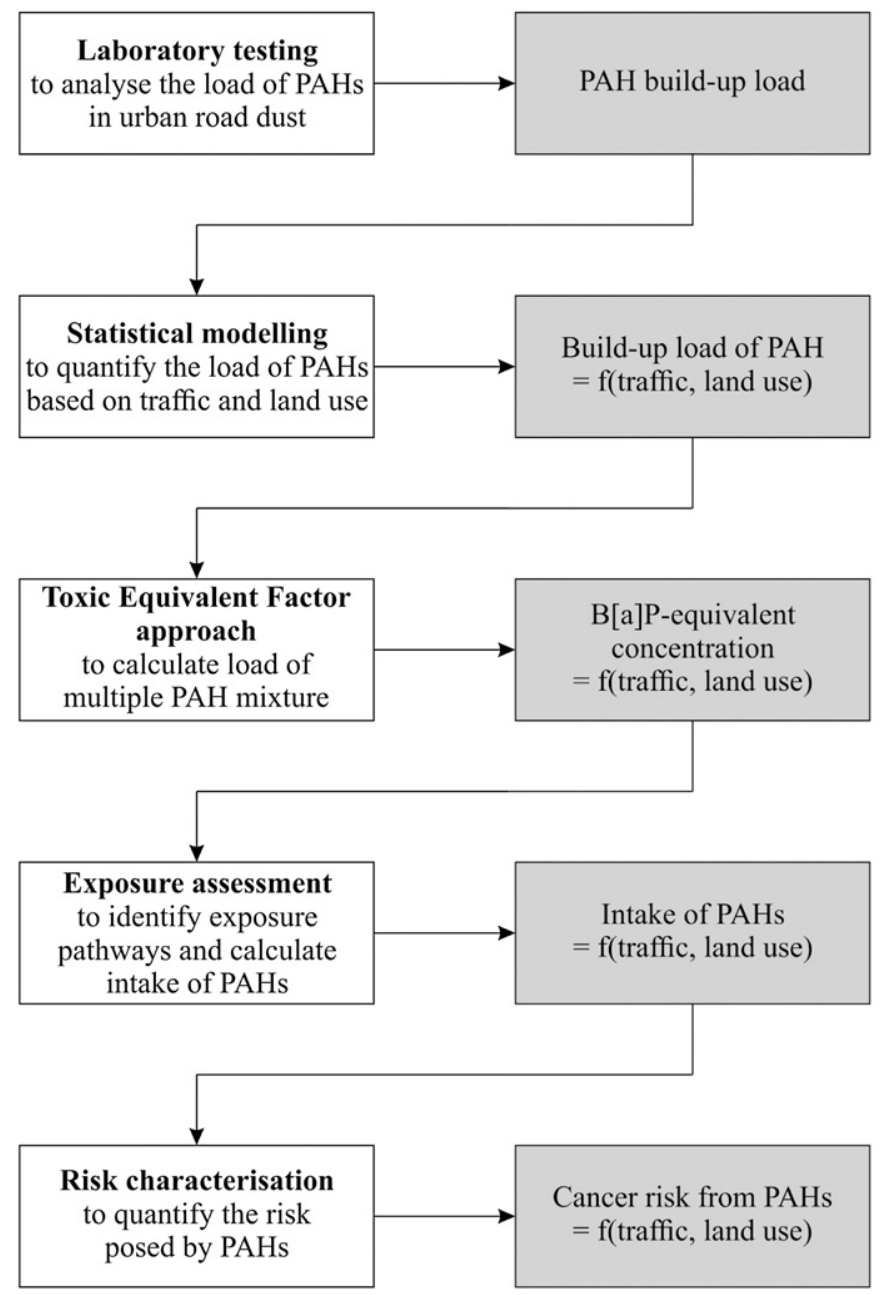

Fig. 2. Methodology flowchart for model development. Note: B[a]Peq - benzo[a]pyrene. land use characteristics. Subsequently, the PAH mixture load was calculated based on the functions derived from the statistical modelling procedure adopted. The PAH mixture load was then used to assess the risk posed by PAHs which is related to traffic and land use characteristics.

\subsection{Statistical modelling}

The statistical modelling was undertaken based on the hypothesis that site-specific build-up of PAHs can be estimated based on traffic and land use due to the significant influence exerted by these factors. Accordingly, the maximum possible PAH load deposited on road surfaces was considered as a standardised form of build-up (independent of antecedent dry days) due to its alignment with the maximum possible risk. In order to estimate the maximum possible risk, PAH build-up load on road surfaces can be estimated using Eq. (1).

$B=f(D T V, C, I, R)$

where $B$ is build-up load of PAHs on road surfaces [ppm]; DTV means daily traffic volumes [average vehicles/day]; $C$, I and $R$ represent the percentage of commercial, industrial and residential land use area [\%].

Eq. (1) was modelled via a linear geostatistical model to account for spatial variability in the build-up data (Ma et al., 2016). In order to ensure the linear relationship between dependent and independent variables, logarithmic transformation of build-up load and DTV was carried out. Accordingly, the expected $\ln B$ was modelled using Eq. (2).

$$
\begin{aligned}
E[\ln B \mid D T V, C, I \text { and } R]= & \beta_{0}+\beta_{1} \times f(\ln D T V)+\beta_{2} \times f(C)+\beta_{3} \\
& \times f(I)+\beta_{4} \times f(R)
\end{aligned}
$$

where $E[\ln B \mid D T V, C, I$ and $R]$ is the expected value of logarithm of PAH build-up load [lnppm]; $\beta_{0}, \beta_{1}, \beta_{2}, \beta_{3}$, and $\beta_{4}$ are the coefficients of the independent variables; $\ln D T V$ is the logarithm of daily traffic volumes [ $\ln$ (average vehicles/day)]; $C, I$ and $R$ represent the percentage of commercial, industrial and residential land use area [\%].

Considering the spatial variability of the build-up data, Eq. (2) was modelled using $\mathrm{R}$ software which provides a conducive environment for geostatistical computing and graphics (Diggle and Ribeiro, 2007). The trend of residuals and independent variables was plotted in $R$ (Fig. 3) and any trend was considered in the modelling procedure as shown in Eq. (2) above and Tables 2 and 3 given below. Fig. 3 is given as an example to show the trend of residual variability of dibenzo[ $a, h]$ anthracene $(\mathrm{D}[a] \mathrm{A})$ associated with total solids and the independent variables. As evident from Fig. 3, it is clear that no trend exists for the residuals variability and therefore, the model fitted the data well. In addition, statistical modelling assumptions about the residuals were checked through diagnostic plots and the agreement between the predicted and observed data was inspected to ensure accuracy. Fig. 4 is an example showing the estimated values against the observed values for the dibenzo[ $a, h]$ anthracene $(\mathrm{D}[a] \mathrm{A})$ load associated with total solids in road dust. It is evident that the data set is distributed evenly along the $y=x$ line as shown in Fig. 4. This indicates that the estimated 

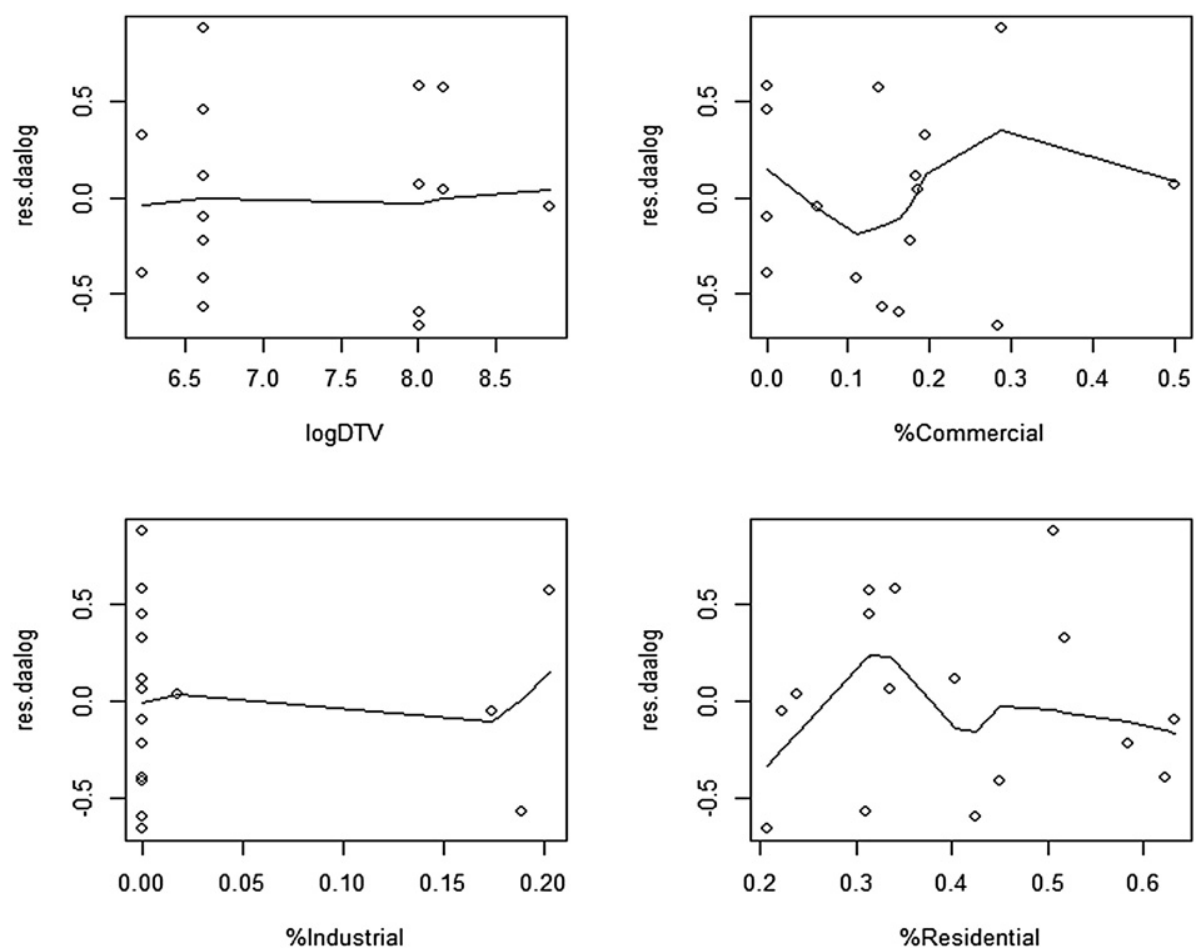

Fig. 3. Estimated residual variability of $\mathrm{D}[\mathrm{a}] \mathrm{A}$ load associated with total solids (trend represented by the line in the plot).

pollutant load approximates to a large extent with the observed data. Similar results were observed for all PAHs.

The final form of the model was determined via Akaike's Information Criterion (AIC) which can be used to select a parsimonious statistical model which describes the data well (Bozdogan, 1987). Accordingly,

Table 2

Equations for estimating PAH load in total solids on a road surface.

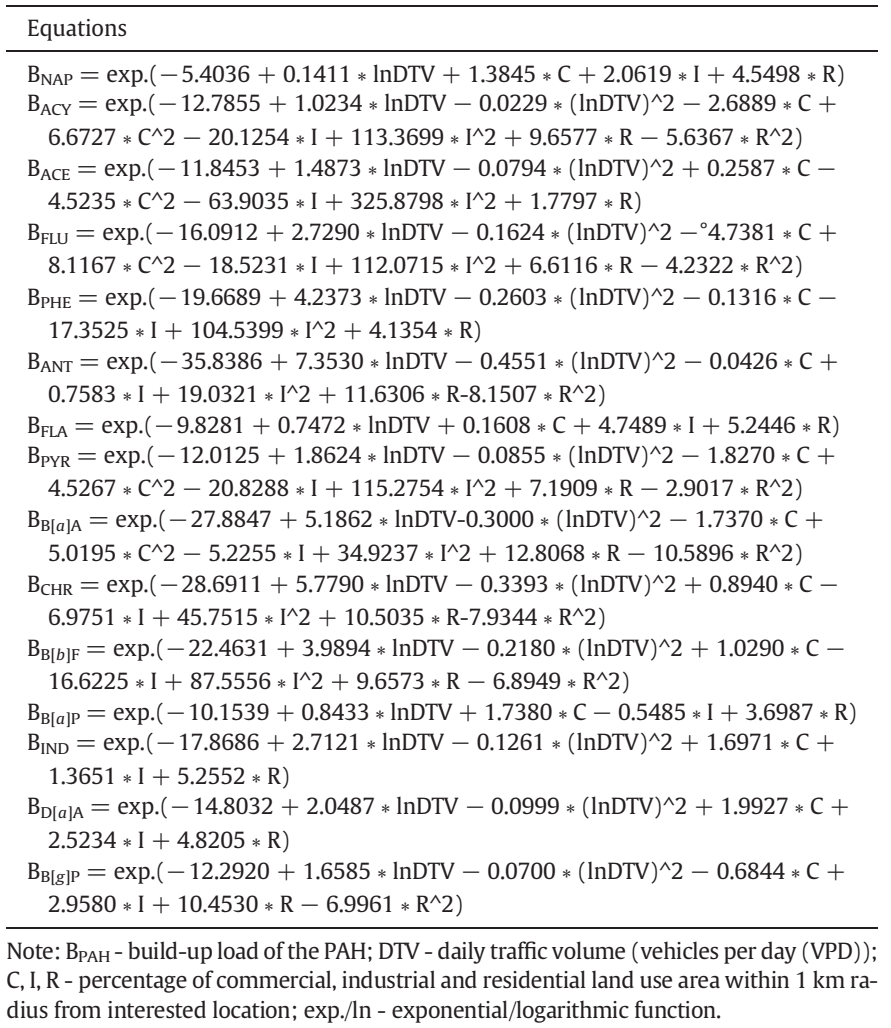

spherical covariance function was selected to describe the spatial variability in the data due to the smallest AIC value derived by this function. The detailed modelling procedure is provided in the Supplementary Information.

Table 3

Equations for estimating PAH load in solids $<150 \mu \mathrm{m}$ on a road surface.

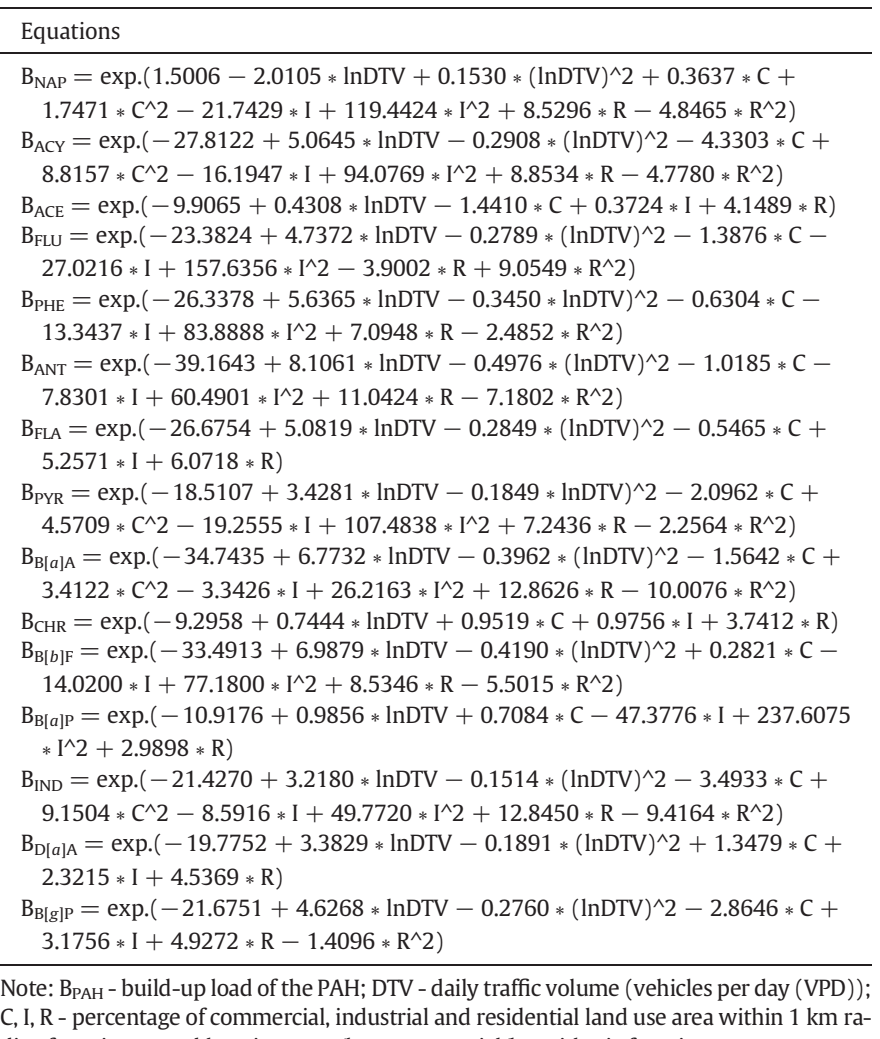
dius from interested location; exp./ln - exponential/logarithmic function. 


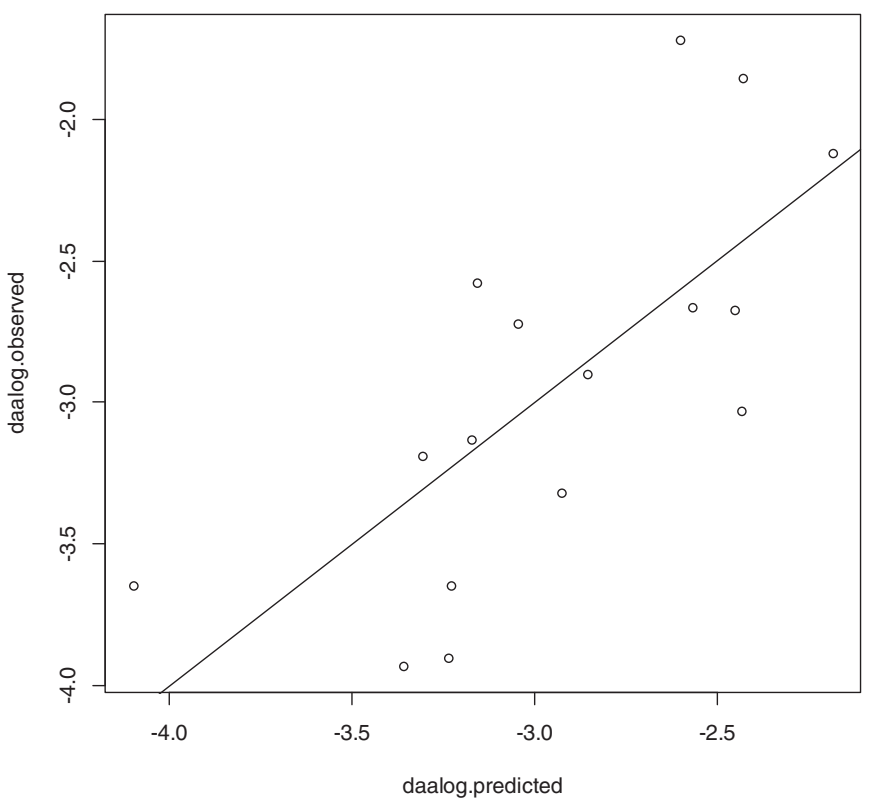

Fig. 4. Distribution of estimated values and observed data for the load of $D[a] A$ associated with total solids.

\subsection{Risk assessment procedure}

\subsubsection{Toxic equivalent factor approach}

Three typical approaches were investigated to assess cancer risk posed by PAHs, namely: (1) benzo[a]pyrene as a surrogate marker; (2) comparative potency approach; and (3) toxic equivalent factor (TEF) approach (Jarvis et al., 2014). The first two approaches were not found to be suitable for this study. The first approach assumes that the composition of PAH mixtures is stable in different exposure scenarios, which is impossible in the natural environment. The second approach requires necessary bioassays which was not practical in this research study, and therefore this approach was also not considered. The third approach is based on the use of toxic equivalent factors (TEFs), and it has been applied in numerous previous studies to evaluate risks from PAHs (Chen and Liao, 2006; Han et al., 2014; Jiang et al., 2014; Khillare et al., 2014; Kumar et al., 2015). Accordingly, the TEF approach was selected for this study to assess risk from PAHs in urban road dust.

The TEF approach adopts benzo[a]pyrene $(\mathrm{B}[a] \mathrm{P})$ as the reference compound due to its highly potent carcinogenic effect and assigns potency factors (i.e. TEFs) relative to $\mathrm{B}[a] \mathrm{P}$ for the other compounds in the mixture. The $\mathrm{PAH}$ mixture load is equivalent to the $\mathrm{B}[a] \mathrm{P}$-equivalent concentration (B[a]P $\mathrm{P}_{\text {eq }}$ ) calculated using Eq. (3) (Jyethi et al., 2014).

$B[a] P_{e q}=\sum_{i=1}^{n} C_{i} \times T E F_{i}+X$

where: $C_{i}$ is the load of the $\mathrm{i}^{\text {th }} \mathrm{PAH}$ detected in the mixture [ppm]; TEF means the TEF value of the $i^{\text {th }}$ PAH detected in the mixture; $n$ is the number of PAHs detected in the mixture; and $X$ stands for the concentration of $\mathrm{B}[a] \mathrm{P}[\mathrm{ppm}]$. TEF values for the PAHs are provided in Table S3 in the Supplementary Information.

\subsubsection{Exposure assessment and risk characterisation}

The $\mathrm{B}[a] \mathrm{P}_{\mathrm{eq}}$ was used to calculate the intake of PAHs in road dust from exposure pathways consisting of ingestion, inhalation and dermal contact with road dust. The exposure pathways identified by US EPA (2002) has been commonly applied in soil science (Khillare et al., 2014; Kumar et al., 2015). An innovation in this study is the adaptation of this procedure for exposure assessment to assess the risk from road dust. The approach is justified on the basis that around 60\% of road dust are sourced from surrounding soil (Gunawardana et al., 2012) and the exposure pathways for humans are similar as in the case of soil. For example, according to US EPA (2002), people could come into contact with fugitive soil through inhalation, and outdoor workers could be exposed to soil through dermal contact. Similarly, pedestrians could inhale re-suspended road dust in the air due to wind and traffic turbulence. Additionally, children could intake road dust through dermal contact and incidental ingestion while playing by the roadside.

Daily intake of PAHs in road dust by an individual adult is described by Eqs. (4), (5) and (6) (US EPA, 1989; US EPA, 2002).

$$
\begin{aligned}
& \text { Intake }_{\text {ing }}=\frac{B[a] P_{\text {eq }} \times I R_{\text {ing }} \times C F \times E F \times E D}{B W \times A T} \\
& \text { Intake }_{\text {inh }}=\frac{B[a] P_{e q} \times I R_{\text {inh }} \times E F \times E D \times \frac{1}{P E F}}{B W \times A T} \\
& \text { Intake }_{d c}=\frac{B[a] P_{e q} \times C F \times S A \times A F \times A B S \times E F \times E D}{B W \times A T}
\end{aligned}
$$

where $B[a] P_{e q}$ is the load of PAH mixture in road dust [ppm]; $I R_{\text {ing }}$ and $I R_{\text {inh }}$ mean ingestion and inhalation rate [mg/day]; $C F$ is conversion factor $\left[10^{-6} \mathrm{~kg} / \mathrm{mg}\right]$; PEF stands for particulate emission factor $\left[\mathrm{m}^{3} / \mathrm{kg}\right] ; S A$ is surface area of the body in contact $\left[\mathrm{cm}^{2}\right] ; A F$ is soil to skin adherence factor $\left[\mathrm{mg} / \mathrm{cm}^{2}\right] ; A B S$ is adsorption factor of benzo[a]pyrene $(\mathrm{B}[\mathrm{a}] \mathrm{P}) ; E F$ and $E D$ represent exposure frequency and duration; $B W$ is body weight [kg]; $A T$ is average time of exposure. The values of the parameters in Eqs. (4), (5) and (6) were selected based on guidance provided by US EPA (1989) to estimate the maximum intake. The parameter values are provided in Table S4 in the Supplementary Information.

The intake of PAHs was used to quantify the cancer risk. The risk posed by PAHs in road dust was represented by the incremental lifetime cancer risk (ILCR) which refers to the probability of an individual who is exposed to PAHs in road dust during his or her lifetime being diagnosed with cancer (US EPA, 2005). ILCR is calculated by multiplying intake with cancer slope factor (CSF) of $\mathrm{B}[a] \mathrm{P}$. CSF is defined as an upperbound of the probability of a response per unit intake of a chemical over a lifetime (US EPA, 1989). According to US EPA (1989), CSF of $\mathrm{B}[a] \mathrm{P}$ through oral ingestion, inhalation and dermal contact are $7.3[\mathrm{mg} / \mathrm{kg} \cdot \text { day }]^{-1}, 3.85[\mathrm{mg} / \mathrm{kg} \cdot \mathrm{day}]^{-1}$ and $25[\mathrm{mg} / \mathrm{kg} \cdot \mathrm{day}]^{-1}$, respectively. The cancer risk from PAHs was calculated using Eq. (7).

$I L C R=$ Intake $\times C S F$

ILCR $<10^{-6}$ is usually considered as negligible while there may be significant concern if ILCR exceeds $10^{-4}$. ILCR that ranges between $10^{-6}$ and $10^{-4}$ is potentially carcinogenic to humans (US EPA, 1989).

\section{Results and discussion}

\subsection{Model setup results}

Build-up load of PAHs associated with fine solids ( $<150 \mu \mathrm{m})$ and coarse solids $(>150 \mu \mathrm{m})$ on urban road surfaces can be predicted based on traffic and land use characteristics according to the rigorous statistical modelling procedure discussed in Section 3.1. Tables 2 and 3 show the predictive equations for estimating PAH loads associated with total solids and fine solids $(<150 \mu \mathrm{m})$, while the PAH load attached to coarse solids was obtained by the difference between the corresponding values of total and fine solids. Any trend between dependent and independent variables was taken into consideration to establish the equations. For example, the quadratic term for $\ln$ DTV in equation to estimate fluoranthene (FLA) load in Table 3 indicates that the trend between $\ln B_{\text {FLA }}$ (FLA load) versus $\operatorname{lnDTV}$ is quadratic, while $\ln B_{\text {FLA }}$ is 
linearly related to $\mathrm{C}$, I and $\mathrm{R}$. This indicates that there would be a highest value of $\ln B_{\text {FLA }}$ depending on lnDTV due to the characteristics of a parabola. On the contrary, there would not be the highest value or the lowest value of $\ln B_{F L A}$ varying with $C$, I and R. Additionally, the higher absolute value of the coefficient represents that $\ln \mathrm{B}_{\mathrm{PAH}}$ (PAH load) is possibly more sensitive to the corresponding independent variable. For example, as evident in Table 2 , the relationship between $\ln B_{A C Y}$ and the independent variables is the same as that in equation $\ln \mathrm{B}_{\mathrm{FLU}}$.

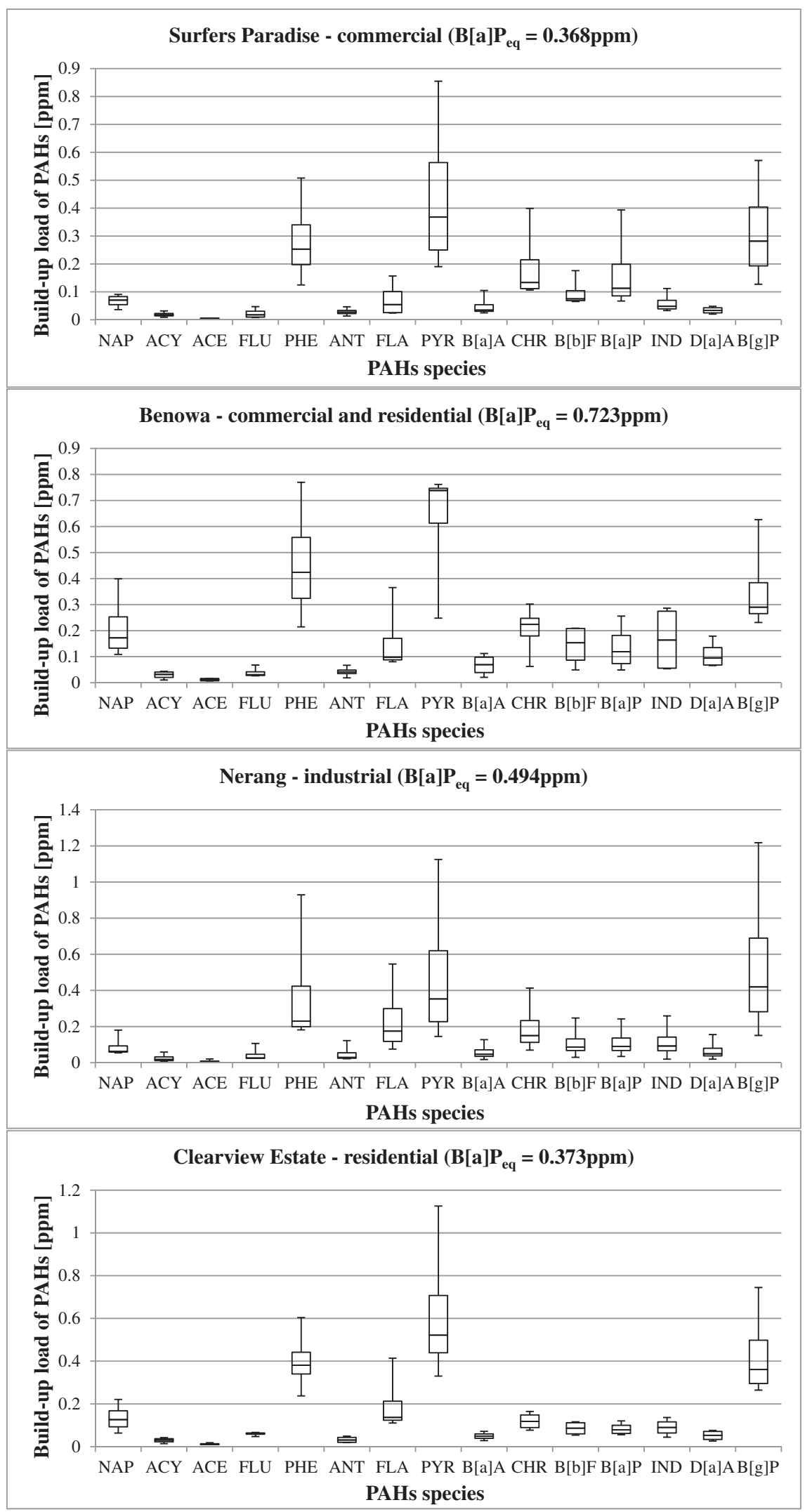

Fig. 5. Build-up load of PAHs in different suburbs. 
However, the absolute value of the coefficient of $\operatorname{lnDTV}(2.7290)$ is higher in the equation $\ln \mathrm{B}_{\mathrm{FLU}}$ than that in $\ln \mathrm{B}_{\mathrm{ACY}}$ (1.0234). Therefore, the build-up load of fluorene (FLU) could be more sensitive to the variation in traffic volume than acenaphthylene (ACY).

Based on the equations to estimate the build-up load of PAHs in Tables 2 and 3, the risk to human health from PAHs in road dust was assessed according to the risk assessment procedure discussed in Section 3.2. Eq. (8) provides the mathematical model developed to estimate cancer risk from PAHs adsorbed to total solids and fine solids on road surfaces, respectively. This model can be applied to an urban area to assess the cancer risk from PAHs in road dust. Based on the inherent traffic and land use characteristics within the urban area, cancer risk assessment of the PAHs in road dust can be undertaken without the need for complex sampling and testing. According to the risk assessment results, the areas with high risk can be identified as hotspots where appropriate management measures need to be taken to minimise the risk.

$$
\begin{aligned}
& \text { Risk }_{P A H}=\frac{1.190789424}{243236} \times 0.001 \times B_{N A P}+0.001 \times B_{A C Y} \\
& \quad+0.001 \times B_{A C E}+0.001 \times B_{F L U}+0.001 \times B_{P H E}+0.01 \times B_{A N T} \\
& \quad+0.001 \times B_{F L A}+0.001 \times B_{P Y R}+0.1 \times B_{B[a] A}+0.01 \times B_{C H R}+0.1 \\
& \quad \times B_{B[b] F}+1 \times B_{B[a] P}+0.1 \times B_{I N D}+5 \times B_{D[a] A}+0.01 \times B_{B[g] P}
\end{aligned}
$$

where: The abbreviations of PAHs are derived from Tables 2 and 3.

Note: Eq. (8) can be used to estimate the risk posed by PAHs on total solids and fine solids on road surfaces.

\subsection{Analysis of PAHs on urban roads in gold coast}

The preliminary build-up load of PAHs was compared in order to derive an initial understanding of the PAH build-up characteristics on road surfaces. The load of each PAH in road dust in different suburbs is presented in Fig. 5 in the form of Box-Whisker plots. As evident from Fig. 5, the most enriched PAHs in road dust are phenanthrene (PHE) (0.12-0.93 ppm), pyrene (PYR) (0.15-1.13 ppm) and benzo[ghi]perylene $(\mathrm{B}[\mathrm{g}] \mathrm{P})(0.13-1.22 \mathrm{ppm})$. The average build-up load of the PAH mixture $\left(\mathrm{B}[a] \mathrm{P}_{\mathrm{eq}}\right)$ on the four road surfaces in each suburb is also shown in Fig. 5. It can be found that the PAH build-up load in Benowa $(0.723 \mathrm{ppm})$ is the highest among the four suburbs which is followed by Nerang (0.494 ppm), while the build-up load of PAHs on road surfaces in Surfers Paradise $(0.368 \mathrm{ppm})$ and Clearview Estate (0.373 ppm) are relatively lower.

The high load of PAHs in road dust in Benowa is attributed to the presence of large amounts of vehicle related business services such as car servicing and petrol stations in the area. Due to the nature of these commercial activities and relatively higher traffic volume, the build-up load of PAHs in Benowa is higher than the other suburbs. Although Surfers Paradise is also a commercial suburb, the main commercial activities are related to retail, education and tourism (Fig. 1) which generate relatively lower PAHs compared to vehicle related business services. Therefore, the PAH load in road dust in Surfers Paradise is lower than in Benowa. The high load of PAHs in road dust in Nerang is attributed to the numerous industrial activities such as painting, timber processing and furniture manufacturing in the area which can generate significant PAH loads (Dong and Lee, 2009; Wang et al., 2011; Bruschweiler et al., 2012; Kho et al., 2014). These results suggested that since areas with vehicle related business activities, high traffic volume and industrial activities can lead to high PAH loads and hence could pose higher risks. Therefore, it is important to pay close attention to urban areas with these types of anthropogenic activities.

\subsection{Cancer risk posed by PAHs in road dust}

Based on Eq. (8), cancer risk to humans posed by PAHs in road dust from the study sites was assessed and the results are given in Fig. 6. Fig. 6 shows that the risk from PAHs deposited on the road surfaces at the study sites are overall in the range from $10^{-6}$ to $10^{-4}$, which implies a potential risk according to Section 3.2.2. This indicates that the PAHs at the study road sites might be carcinogenic through ingestion, inhalation or dermal contact with road dust. From Fig. 6, it can also be seen that the risk posed by PAHs associated with fine solids (ILCR-fine) is generally much higher than that with coarse solids (ILCR-coarse). The contribution of risk from PAHs adsorbed to fine solids to the total risk from the PAH mixture in urban road dust ranges from $65.91 \%$ to $98.56 \%$ while the percentage is $1.44 \%$ to $34.09 \%$ for the contribution from coarse solids. This confirms that the potential cancer risk from PAHs in road dust is mainly influenced by the PAHs associated with fine solids. In other words, PAHs associated with fine road dust can pose cancer risk to humans while the PAHs associated with coarse solids do not pose a

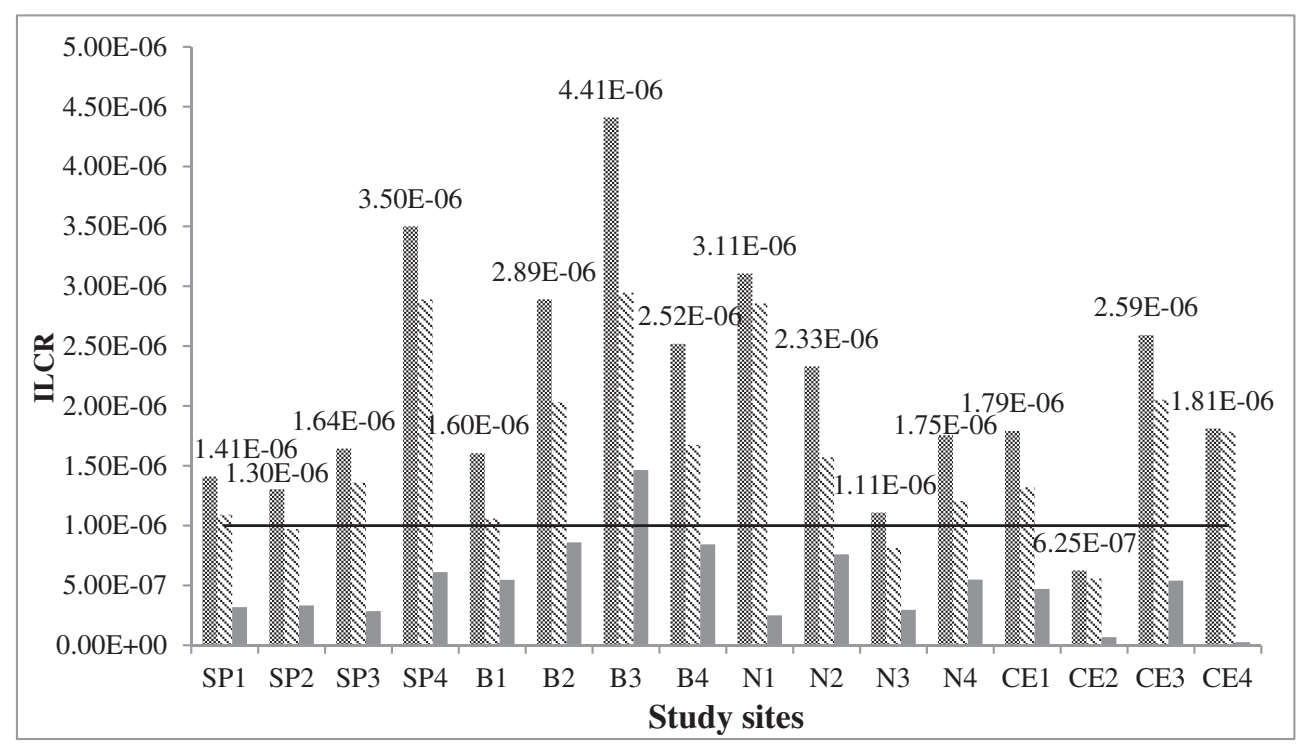

$$
\text { Total solids Coarse solids } \quad \text { 1E-06 }
$$


Table 4

Contribution of a single PAH to the combined risk from multiple PAHs.

\begin{tabular}{lll}
\hline PAHs & Number of benzene rings & Contribution to the risk from multiple PAHs \\
\hline D $[a] A$ & 5 & $66.54 \%$ \\
B $[a] P$ & 5 & $26.03 \%$ \\
B $[b] \mathrm{F}$ & 5 & $2.42 \%$ \\
IND & 6 & $2.14 \%$ \\
B $[a] A$ & 4 & $1.24 \%$ \\
B $[g] P$ & 6 & $0.87 \%$ \\
CHR & 4 & $0.40 \%$ \\
PYR & 4 & $0.12 \%$ \\
ANT & 3 & $0.08 \%$ \\
PHE & 3 & $0.08 \%$ \\
FLA & 4 & $0.03 \%$ \\
NAP & 2 & $0.03 \%$ \\
FLU & 3 & $0.01 \%$ \\
ACY & 3 & $0.01 \%$ \\
ACE & 3 & $0.00 \%$ \\
\hline
\end{tabular}

risk to human health. Fig. 6 also confirms that the risk from PAHs associated with fine solids are generally over $10^{-6}$, while the risk from PAHs associated with coarse solids are overall $<10^{-6}$. As mentioned in Section 3.2.2, $10^{-6}$ is the threshold for the non-risk and potential risk posed by PAHs. This suggests that fine solids in road dust require relatively more attention in order to minimise the overall risk posed by PAHs.

The contribution of a single $\mathrm{PAH}$ to the combined risk from multiple PAHs is given in Table 4. This was calculated by multiplying the average load of each PAH from the 16 road sites with the corresponding TEF value. As evident from Table 4, the contribution to the risk by PAHs with relatively heavier molecular weight ( 5 or 6 benzene rings) is generally higher than the contribution from PAHs with lighter molecular weight ( 2 to 4 benzene rings). According to Fig. 5, the load of phenanthrene (PHE), pyrene (PYR) and benzo[ghi]perylene $(\mathrm{B}[\mathrm{g}] \mathrm{P})$ are the highest among all the PAHs. However, these three PAHs make a relatively small contribution to the combined risk posed by the PAH mixture. Table 4 shows that dibenzo[ $a, h]$ anthracene $(\mathrm{D}[a] \mathrm{A})$ and benzo[ $[a]$ pyrene $(\mathrm{B}[a] \mathrm{P})$ contribute the most to the risk posed by the PAH mixture due to their relatively higher toxic equivalent factors. However, the load of dibenzo[a,h]anthracene $(\mathrm{D}[a] \mathrm{A})$ and benzo[a]pyrene $(\mathrm{B}[a] \mathrm{P})$ in road dust is much less than phenanthrene (PHE), pyrene (PYR) and benzo[ghi]perylene $(\mathrm{B}[g] \mathrm{P})$. This implies that dibenzo[ $a, h]$ anthracene $(\mathrm{D}[a] \mathrm{A})$ and benzo[a]pyrene $(\mathrm{B}[a] \mathrm{P})$ are significantly carcinogenic even at low concentrations. Therefore, the risk from PAHs in urban road dust is primarily influenced by the heavy PAHs with 5 to 6 benzene rings, especially dibenzo[a,h]anthracene $(\mathrm{D}[a] \mathrm{A})$ and benzo[ $a]$ pyrene $(\mathrm{B}[a] \mathrm{P})$. This suggests that the management of risk from PAHs in urban road dust should primarily focus on reducing the build-up load of heavy PAHs, especially dibenzo[a,h]anthracene $(\mathrm{D}[a] \mathrm{A})$ and benzo[a]pyrene $(\mathrm{B}[a] \mathrm{P})$ on road surfaces.

\section{Conclusions}

The study discussed in this paper developed a quantitative model to assess the risk to human health from PAHs in fine and coarse road dust based on daily traffic volume and urban land use. The main outcomes of the study are:

- Vehicle related commercial activities and industrial activities can contribute to high PAH load in urban road dust because of the nature of the anthropogenic activities and the relatively high traffic volume generated.

- The study discussed in this paper confirms that PAHs associated with fine road dust can pose cancer risk to humans while the PAHs adsorbed to coarse solids are generally safe to human health. This implies that the potential cancer risk from PAHs in road dust is mainly influenced by the PAHs associated with fine solids.
- The risk from PAHs in urban road dust is primarily influenced by the heavy PAHs with 5 to 6 benzene rings, especially dibenzo[ $a, h]$ anthracene $(\mathrm{D}[a] \mathrm{A})$ and benzo[a]pyrene $(\mathrm{B}[\mathrm{a}] \mathrm{P})$, which are significantly carcinogenic even at low concentrations.

Based on the study outcomes, following practical approaches are recommended to manage the risk in relation to PAHs in urban road dust:

- Based on the traffic and land use characteristics within an urban area, the risk posed by PAHs in road dust can be estimated without complex sampling and testing having to be undertaken. Hotspots can be identified where appropriate measures need to be implemented in order to minimise the risk.

- Since areas with vehicle related business activities, high traffic volume and industrial activities can lead to high risk from PAHs, it is important to pay close attention to urban areas with these types of anthropogenic activities.

- Fine solids in road dust need to be afforded more attention in order to minimise the risk in relation to PAHs.

- Management of risk posed by PAHs in urban road dust should focus on reducing the build-up load of heavy PAHs, especially dibenzo[a,h]anthracene $(\mathrm{D}[a] \mathrm{A})$ and benzo[a]pyrene $(\mathrm{B}[a] \mathrm{P})$ on urban road surfaces.

\section{Funding}

This research did not receive any specific grant from funding agencies in the public, commercial, or not-for-profit sectors.

\section{Acknowledgements}

The authors would like to acknowledge the Chinese Scholarship Council (CSC) and Queensland University of Technology (QUT) for the scholarship provided to the first author for undertaking this doctoral study and Gold Coast City Council for providing baseline data.

\section{Appendix A. Supplementary data}

The supplementary information provided contains the original dataset of PAH loads collected from each road surface, detailed information about the statistical modelling procedure, toxic equivalent factors for PAHs and parameters to calculate the intake of PAHs in road dust. Supplementary data associated with this article can be found in the online version, at http://dx.doi.org/10.1016/j.scitotenv.2016.09.148.

\section{References}

Amato, F., Pandolfi, M., Viana, M., Querol, X., Alastuey, A., Moreno, T., 2009. Spatial and chemical patterns of PM10 in road dust deposited in urban environment. Atmos. Environ. 43 (9), 1650-1659.

APHA, 2004. Standard Methods for the Examination of Water and Wastewater. American Public Health Association, American Water Works Association, Water Environment Federation, Washington DC.

Bozdogan, $\mathrm{H}$, 1987. Model selection and Akaike's information criterion (AIC): the general theory and its analytical extensions. Psychometrika 52 (3), 345-370.

Brown, J.N., Peake, B.M., 2006. Sources of heavy metals and polycyclic aromatic hydrocarbons in urban stormwater runoff. Sci. Total Environ. 359 (1-3), 145-155.

Bruschweiler, E.D., Danuser, B., Huynh, C.K., Wild, P., Schupfer, P., Vernez, D., Boiteux, P., Hopf, N.B., 2012. Generation of polycyclic aromatic hydrocarbons (PAHs) during woodworking operations. Front. Oncol. 2.

Chen, S.-C., Liao, C.-M., 2006. Health risk assessment on human exposed to environmental polycyclic aromatic hydrocarbons pollution sources. Sci. Total Environ. 366 (1), $112-123$.

Diggle, P., Ribeiro, P.J., 2007. Model-Based Geostatistics. Springer Science \& Business Media, New York

Dong, T.T.T., Lee, B.-K., 2009. Characteristics, toxicity, and source apportionment of polycylic aromatic hydrocarbons (PAHs) in road dust of Ulsan, Korea. Chemosphere 74 (9), 1245-1253. 
Egodawatta, P., Thomas, E., Goonetilleke, A., 2009. Understanding the physical processes of pollutant build-up and wash-off on roof surfaces. Sci. Total Environ. 407 (6), 1834-1841.

ESRI, 2016. ArcGIS Help 10.4. Retrieved 09 May, 2016, from http://resources.arcgis.com/ EN/HELP/MAIN/10.1/index.html\#//00qn0000013t000000.

Fang, G.-C., Chang, K.-F., Lu, C., Bai, H., 2004. Estimation of PAHs dry deposition and BaP toxic equivalency factors (TEFs) study at urban, industry park and rural sampling sites in central Taiwan, Taichung. Chemosphere 55 (6), 787-796.

Google, 2015. Earth Help. Retrieved 08 December, 2015, from https://support.google. com/earth/?hl=en\#topic $=4363013$.

Gunawardana, C., Egodawatta, P., Goonetilleke, A., 2014. Role of particle size and composition in metal adsorption by solids deposited on urban road surfaces. Environ. Pollut. 184, 44-53.

Gunawardana, C., Goonetilleke, A., Egodawatta, P., Dawes, L., Kokot, S., 2012. Source characterisation of road dust based on chemical and mineralogical composition. Chemosphere 87 (2), 163-170.

Gunawardena, J., Egodawatta, P., Ayoko, G.A., Goonetilleke, A., 2012. Role of traffic in atmospheric accumulation of heavy metals and polycyclic aromatic hydrocarbons. Atmos. Environ. 54, 502-510.

Gunawardena, J., Egodawatta, P., Ayoko, G.A., Goonetilleke, A., 2013. Atmospheric deposition as a source of heavy metals in urban stormwater. Atmos. Environ. 68, 235-242.

Gunawardena, J., Ziyath, A.M., Egodawatta, P., Ayoko, G.A., Goonetilleke, A., 2014. Influence of traffic characteristics on polycyclic aromatic hydrocarbon build-up on urban road surfaces. Int. J. Environ. Sci. Technol. 11 (8), 2329-2336.

Han, J., Zhang, N., Niu, C., Han, B., Bai, Z., 2014. Personal exposure of children to particleassociated polycyclic aromatic hydrocarbons in Tianjin, China. Polycycl. Aromat. Compd. 34 (4), 320-342.

Holmes Jr., K.K., Shirai, J.H., Richter, K.Y., Kissel, J.C., 1999. Field measurement of dermal soil loadings in occupational and recreational activities. Environ. Res. 80 (2), $148-157$.

Jarvis, I.W., Dreij, K., Mattsson, Å., Jernström, B., Stenius, U., 2014. Interactions between polycyclic aromatic hydrocarbons in complex mixtures and implications for cancer risk assessment. Toxicology 321, 27-39.

Jiang, Y., Hu, X., Yves, U.J., Zhan, H., Wu, Y., 2014. Status, source and health risk assessment of polycyclic aromatic hydrocarbons in street dust of an industrial city, NW China. Ecotoxicol. Environ. Saf. 106, 11-18.

Jyethi, D.S., Khillare, P., Sarkar, S., 2014. Risk assessment of inhalation exposure to polycyclic aromatic hydrocarbons in school children. Environ. Sci. Pollut. Res. 21 (1), 366-378.

Khillare, P., Hasan, A., Sarkar, S., 2014. Accumulation and risks of polycyclic aromatic hydrocarbons and trace metals in tropical urban soils. Environ. Monit. Assess. 186 (5), 2907-2923.

Kho, Y., Lee, E.-H., Chae, H.J., Choi, K., Paek, D., Park, S., 2014. 1-Hydroxypyrene and oxidative stress marker levels among painting workers and office workers at shipyard. Int. Arch. Occup. Environ. Health 88, 297-303.
Kumar, B., Verma, V., Sharma, C., Akolkar, A., 2015. Estimation of toxicity equivalency and probabilistic health risk on lifetime daily intake of polycyclic aromatic hydrocarbons from urban residential soils. Hum. Ecol. Risk. Assess. 21 (2), 434-444.

Ma, Y., Egodawatta, P., McGree, J., Liu, A., Goonetilleke, A., 2016. Human health risk assessment of heavy metals in urban stormwater. Sci. Total Environ. 557-558, 764-772.

Mahler, B.J., Metre, P.C.V., Crane, J.L., Watts, A.W., Scoggins, M., Williams, E.S., 2012. Coaltar-based pavement sealcoat and PAHs: implications for the environment, human health, and stormwater management. Environ. Sci. Technol. 46 (6), 3039-3045.

Novotny, V., Sung, H.M., Bannerman, R., Baum, K., 1985. Estimating nonpoint pollution from small urban watersheds. J. Water Pollut. Control Fed. 57 (4), 339-348.

Peng, C., Wang, M., Zhao, Y., Chen, W., 2016. Distribution and risks of polycyclic aromatic hydrocarbons in suburban and rural soils of Beijing with various land uses. Environ. Monit. Assess. 188 (3), 1-12.

Rocher, V., Azimi, S., Gasperi, J., Beuvin, L., Muller, M., Moilleron, R., Chebbo, G., 2004. Hydrocarbons and metals in atmospheric deposition and roof runoff in central Paris. Water Air Soil Pollut. 159 (1), 67-86.

Shi, S., Huang, Y., Zhou, L., Yang, W., Dong, L., Zhang, L., Zhang, X., 2013. A preliminary investigation of BDE-209, OCPs, and PAHs in urban road dust from Yangtze River Delta, China. Environ. Monit. Assess. 185 (6), 4887-4896.

Tsai, P.-J., Shieh, H.-Y., Hsieh, L.-T., Lee, W.-J., 2001. The fate of PAHs in the carbon black manufacturing process. Atmos. Environ. 35 (20), 3495-3501.

US EPA, 1984. Guidelines Establishing Test Procedures for the Analysis of Pollutants Under Clean Water Act: Method 610 - Polynuclear Aromatic Hydrocarbons. 49. US Environmental Protection Agency, Washington, DC, pp. 43344-43352.

US EPA, 1989. Risk Assessment Guidance for Superfund, Volume I, Human Health Evaluation Manual (Part A). US Environmental Protection Agency, Washington, DC.

US EPA, 1996. Pressurized Fluid Extraction (PFE). US Environmental Protection Agency, Washington, DC.

US EPA, 2002. Supplemental Guidance for Developing Soil Screening Levels for Superfund Sites. US Environmental Protection Agency, Washington, DC.

US EPA, 2005. Human Health Risk Assessment Protocol for Hazardous Waste Combustion Facilities. US Environmental Protection Agency, Washington, DC.

Wang, W., Huang, M.-j., Kang, Y., Wang, H.-s., Leung, A.O.W., Cheung, K.C., Wong, M.H., 2011. Polycyclic aromatic hydrocarbons (PAHs) in urban surface dust of Guangzhou, China: status, sources and human health risk assessment. Sci. Total Environ. 409 (21) 4519-4527.

Wijesiri, B., Egodawatta, P., McGree, J., Goonetilleke, A., 2016. Assessing uncertainty in pollutant build-up and wash-off processes. Environ. Pollut. 212, 48-56.

Wu, G., Kechavarzi, C., Li, X., Sui, H., Pollard, S.J., Coulon, F., 2013. Influence of mature compost amendment on total and bioavailable polycyclic aromatic hydrocarbons in contaminated soils. Chemosphere 90 (8), 2240-2246.

Yu, G., Zhang, Z., Yang, G., Zheng, W., Xu, L., Cai, Z., 2014. Polycyclic aromatic hydrocarbons in urban soils of Hangzhou: status, distribution, sources, and potential risk. Environ. Monit. Assess. 186 (5), 2775-2784.

Zhu, Y., Hinds, W.C., Kim, S., Shen, S., Sioutas, C., 2002. Study of ultrafine particles near a major highway with heavy-duty diesel traffic. Atmos. Environ. 36 (27), 4323-4335. 